\title{
A HOSPITALIZAÇÃO DA CRIANÇA SOB ABORDAGEM DE CUIDADOS PALIATIVOS E AS VIVÊNCIAS MATERNAS
}

\author{
Felipe Leonardo Rigo \\ Fundação Hospitalar do Estado de Minas Gerais - FHEMIG \\ felipeleonardorigo@hotmail.com \\ Marcelle Stephane Nunes de Oliveira \\ Hospital Infantil João Paulo II \\ Fundação Hospitalar do Estado de Minas Gerais - FHEMIG \\ marcellesnunes92@gmail.com \\ Elizabeth Iracy Alves Leite \\ Hospital Infantil João Paulo II \\ Fundação Hospitalar do Estado de Minas Gerais - FHEMIG \\ bebel.leite@gmail.com
}

\section{RESUMO}

INTRODUÇÃO: As doenças raras e crônicas infantis repercutem na vida da criança e sua família, são responsáveis por mudanças na dinâmica familiar e alterações de papéis e podem contribuir para o desgaste psicológico e econômico familiar e nesta situação, aspectos ultrapassam as dimensões do cuidado habitual. A hospitalização da criança e o processo de internação prolongado pode ocasionar o aumento do estresse e desequilíbrio entorno dos familiares, porém, algumas destas se fortalecem e conseguem experienciar de forma positiva as situações adversas e estressoras. OBJETIVO: Compreender a vivência materna frente a hospitalização da criança com abordagem paliativa. METODOLOGIA: Estudo qualitativo, realizado na unidade de Cuidados Paliativos de um hospital da rede estadual de saúde em Minas Gerais. Os dados foram coletados entre os meses de agosto de 2019 a janeiro de 2020 por meio de entrevista, com questões fundamentadas no modelo Resiliência, Estresse, Ajustamento e Adaptação Familiar de McCubbin e McCubbin. Estudo aprovado pelo Comitê de Ética e Pesquisa da Fundação Hospitalar do Estado de Minas Gerais (FHEMIG) sob o parecer $\mathrm{n}^{\circ}$ 3.494.62I. RESULTADOS: Foram entrevistadas oito mães, com idades variando entre 2I a 45 anos. Em relação ao estado civil quatro eram casadas, a maioria das participantes não residia na cidade, cenário do estudo, e este fato deve-se ao perfil de atendimento da instituição, a qual é referência para todo o estado de Minas Gerais. Quanto ao grau de escolaridade três tinha ensino médio completo. A maioria das participantes não possuía emprego na ocasião da entrevista. Acerca da renda familiar mensal, cinco participantes declararam renda igual ou inferior um salário mínimoO longo período de internação foi descrito como frustrante e angustiante. O recebimento do diagnóstico foi vivenciado como um evento estressor associado ao desespero, preocupação e tristeza. Todas as mães relatam que foram encorajadas e treinadas para realizar os cuidados com suas crianças. Mudança de domicílio, absenteísmo e alteração no turno de trabalho foram elencadas como alteração na rotina familiar. Como estratégias de enfrentamento foram citadas a calma e o bom diálogo. Entidades religiosas, parentes e os próprios profissionais de saúde foram mencionados como suporte social e de apoio emocional. CONCLUSÃO: É imperativo que haja maiores investigações da percepção materna frente a internação da criança em uma perspectiva paliativista.

PALAVRAS-CHAVE: Cuidados Paliativos; Mães, Pediatria. 